\title{
Elementary Principal Perception of the Texas Principal Evaluation Support System (T-Pess)
}

\author{
Clarence Williams, Ed.D \\ Managing Director for Secondary Schools \\ Frisco Independent School District \\ Frisco, Texas, United States \\ Melissa Arrambide, Ed.D \\ Associate Professor \\ Master's Degree \& Principal Certification Coordinator \\ Texas A \& M University Commerce \\ Department of Educational Leadership \\ United States
}

Chuck Holt, Ed.D.

Associate Professor

Doctoral Degree Program Coordinator

Texas A \& M University Commerce

Department of Educational Leadership

United States

\begin{abstract}
The new era of school reform initiatives by federal and legislative mandates at the state level has ushered in a level of increased importance being placed on the evaluation of principals. The purpose of this research study specifically was to explore elementary principals' perceptions of the usefulness of the Texas Principal Evaluation Support System (TPESS) evaluation process in enhancing their leadership capacity and growth. Criterion sampling was used in this research study. Afast-growth North Texas school district was selected for this study based on the assumption that the principals within that district possess knowledge and experience with the phenomenon of interest (i.e., the implementation of T-PESS) and thus wereable to provide information that is both detailed and broad in perspective. From the perspective of qualitative research methodology, the district selected is representative of the larger population because it meets the same criteria, which, in this case, performs an explicit role in the implementation of the T-PESS evaluation process. The study participants werecomprised of 10 elementary campus principals, with each participant in the study meeting the following criteria: (a) has a minimum 2 years of experience as a principal, (b) works on a campus that has been established for at least 3 years, and (c) is currently participating in the T-PESS evaluation systems in the state of Texas. The data for this qualitative study were collected from questionnaire responses and semi-structured interviews.
\end{abstract}

Keywords: Principal, Principal Evaluation, Texas Principal Support System, School Leadership

\section{Introduction}

Principals, asleaders of schools, work to provide guidance in discipline, policies, and procedures, as well as to positively influence teachers, parents, and the community. Principals' roles are crucial in creating safe learning environments, hiring and evaluating personnel, and practicing ethical principles and handling issues of conflict (Cisler\&Bruce, 2013). As leaders, principals are evaluated throughout their time serving schools by a variety of instrumental tools used nationwide to assess the performance of the administrators. However, the use of such evaluative tools is not standardized, and while results on performance may be provided, theidea of potential growth and improvement for those principals being evaluated is not being explored (Shepard, Penuel, \& Davidson, 2017). To develop more effective leadership within schools, it is important to identify the perceptions and experiences of principals on their own potential growth and performance. 
According to the National Association of Elementary School Principals (NAESP, 2017), school administratorslack an effective way to evaluate the performance of principalsinregard to the complexity of the job,the competencies associated with the position, and the reflection of principal insight. Furthermore, the federal government has askedstates to develop their own systems for principal evaluations; as a result, several states have implemented their own approaches forassessing the performance of campus principals (NAESP, 2017).

Districts are given a choice in Texas to develop their own principal evaluation system or to use T-PESS (TEA, 2017). If T-PESS is the chosen process, the initial step is for district personnelto provide an orientation for principals about the evaluation process. The appraiser will then conduct informal visits and assessments by visiting the school and assessing the principal's performance. A mid-year meeting between the principal and appraiser then takes place to review goals, reflect on the rubric, and analyze current performance. At this meeting, the principal learnswhetherhe or she is progressing towardachieving his or her goals. The principal is responsible for collecting and gathering evidence to demonstrate meeting his or her goals and for sharing the evidence at the final meeting during an end-of-year conference. During the third and final phase, the appraiser gives a summative assessment of goal attainment and works collaboratively with the principal to assess overall performance as well as establish goals for the next school year.

Many studies on the perceptions of principals can be found in the literature,such as studies thathave explored their perceptionsonteacher evaluation, program implementation, and their influence on teacher effectiveness (Tran, 2015). Research on strategies, like Gunbayi's(2011) work on principal perceptions, has focused on the management of the school and how principals describe the performance of students.Specifically, this study focused on the perception of elementary principals as it relates to T-PESS.

\section{Perspective}

The theoretical framework of empirical rational theory guided the development of this study. Findings from research conducted on principal evaluation systems, thus far, have demonstrated a need for participants in the programs to understand change and the creation of more responsive systems using theory, particularly the empirical rational theory. Researchers Nickols (2016) and Quinn and Sonenshein (2008), developers of the empirical rational theory, presented the idea that people are rational and change can be successfully accomplished by communicating information and offering incentives.

The change in leadership behavior, particularly the skills related to leadership capacity and growth, can be applied to the empirical rational theory. Principals participating in the evaluative process need to understand why improvement should be made, what needs to change, and why it is necessary that these areas of improvement be addressed. Without an understanding of one's ability and growth levels and goals to improve in these areas, principals cannot perceive their own growth through lack of self-interest, as is explained in the theory (Quinn \&Sonenshein, 2008).

\section{Purpose Statement}

The purpose of this qualitative research study was to explore elementary principals' perceptions of the usefulness of TPESS in enhancing their leadership capacity and growth. The researcher sought to understand how elementary principals perceive the T-PESS evaluation and if it is beneficial in enhancing their professional growth. Currently, there are challenges to achieving growth for principals;indeed,some have identified barriers such as conflicting priorities,efforts to appease multiple stakeholders, and notenough time to meet all the demands related to the complexities of the principalshipas challenges that impede growth (NASSP \&NAESP, 2013). This study represents a logical response to the lack of information available concerning how elementary principals perceive the T-PESS evaluation process.

\section{Review of Literature}

Evaluation as a process for assessing the performance of educational leaders working within schools became increasingly important as schools developed into larger organizations. The first formal educator evaluation occurred in Boston in 1845and was designed to measure and assess the knowledge and skills of educators (Marzano et al., 2011). Following World War II, emphasis was placed on using educator evaluations in order to determine opportunities for improvement and identify areas to focus on in professional development (Marzano et al., 2011). Research on evaluation systems and processes historically has been inclusive of challenges based on researchers asserting that principal performance and growth cannot be determined through evaluative measures (Fuller \& Hollingsworth, 2014). Moreover, several research studies have indicated that the adoption of new principal evaluation systems were in fact often perceived as counterproductive by principals (Anderson, 2012). 
The research literature regarding principal evaluation is minimal. However, the topic is becoming more prominent sinceempirical studies have begun connecting principal growth with evaluations and effective leadership in schools (Hvidston et al., 2015). As research progressed into the 2000s, it was determined that several principal evaluation processes were not aligned with standards (Marcoulides et al., 2005). Subsequently, the Interstate School Leaders Licensure Consortium standards were the first principal performance standards developed that were aligned to the principal evaluation process (Derrington\&Sharratt, 2008; Yavuz, 2010).

Furthermore, although several research studies have documented the perception of other stakeholders within school organizations regarding the qualities of principal leadership, very few studies have included the perception of principals regarding the impact of evaluation processes on their professional growth (Arar et al., 2016; Moore et al., 2016). However, organizations such as NASSP and NAESP are increasingly participating in research studies to ensure states are adopting principal evaluation instruments intended to optimize principal professional growth (Krasnoff, 2015).

In addition, federal school reform initiatives and legislative mandates have led many states to begin the process of redefining and recreating their own principal evaluation system and processes. Moreover, federal and state policies for principal certifications and licensure have become influential in requiring states to develop principal preparation programs linked to enhancing the growth and development of principals (Anderson \& Reynolds, 2015). However, as indicated in the research literature, several principal preparation and licensure programs fail to produce highly qualified potential principal candidates. The legal requirements for principals to be certified are based on ensuring that potential candidates for the principalship have the necessary knowledge and skills to accomplish the responsibilities thatencompass operating a school facility (Anderson \& Reynolds, 2015). Moreover, the research literature emphasizes four components associated with principal licensure and certification: (a) experience-principal candidates should have classroom instruction experience as well as preferably possess a graduate degree in education administration; (b) assessment - potential principal candidates are required to achieve a passing score on the certification exam; (c) renewal-once principals are hired, they are required to participate in continuing professional educator learning to ensure hours are accrued for professional development; and (d) alternative licensure pathway-given the need for highly qualified principal candidates, several states have refined and created alternative methods of licensure in addition to traditional pathways. The State of Texas has clearly articulated the legal requirements for principal certification in the Texas Administrator Code, Chapter 241 (TEA, 2017). Furthermore, the State of Texas strategically abandoned the former PDAS, which was considered evaluative, in order to implement the new T-PESS evaluation, which is focused on professional growth (TEA, 2017). Again, the legal requirements for principal appraisal is outlined in the Texas Education Code, Section 21 (TEA, 2017).

Principal evaluation can be impactful when conducted with fidelity and used to reflect the performance of principals with authentic feedback and support (Clifford \& Ross, 2011). As stated in the literature, the primary purpose of the TPESS evaluation process is to increase and enhance principals' professional capacity. Moreover, the T-PESS evaluation process involves four components, which include the following:

- Self-assessment.

- Beginning-of-year conference and goal setting.

- Mid-year conference.

- End-of-year conference.

When principals are knowledgeable regarding the process utilized to evaluate their performance, they are more prone to trust the process rather than view it as a perfunctory measure. Furthermore, the five standards outlining the criteria for principals - (a) instructional leadership, (b) human capital, (c) executive leadership, (d) school culture, and (e) strategic operation - each identify the dimensions whereby principals are rated from developing to distinguished. Based on the research, if an evaluation process is to be meaningful and result in professional growth elements, professional development should be an integral part of the evaluation process. Emerging research continues to reflect that principal evaluation processes are critically important and should assist principals in understanding what motivate others andshould also provide a mechanism for them to uncover their own strengths andweaknesses and identify strategies to enhance their professional growth.

\section{Methods and Procedures}

Qualitative research methodology was used in this study because the method is widely accepted in social sciences and educational settings when the researcher seeks to gain the perceptions of humans by asking questions (Creswell, 2013). Qualitative methodology is particularly appropriate when the research questions start with "how" or "what," which indicates that the perspective being studied is complex and has no definitive theory (Creswell, 2014). 
In this study, the researcher employed a narrative inquiry research design to examine the perception and experiences of elementary school principals engaged in the T-PESS evaluation process and to examine what components they find useful. The importance of narrative inquiry is emphasized by Clandinin and Connelly (2000): "Narrative inquiry focus on the aspects of qualitative inquiry that prioritize the experience of the individual and personal experience is understood most effectively through the stories people live" (p. 107). Moreover, narrative inquiry design afforded the researcher the opportunity to gain significant insights into real-life events of principals and their experiences (Creswell, 2014).

The principals' stories provided perceptions and experiences of what parts or components of the T-PESS evaluation process they found most useful, what challenges they have faced within the evaluation process, how the process facilitates new learning, the role of the T-PESS standards in the evaluation of the principal, and the impact of learning and growth. By providing the elementary principal participants the ability to respond to questions about their own experiences, they were able to express personal and firsthand accounts of their involvement with the T-PESS evaluation process that provided helpful insights into their perceptions of the usefulness of the evaluation process

This study used a questionnaire, followed by an interview, to determine perceptions and experiences of elementary school principals regarding T-PESS. The following central questions guided the research for this study:

1. What components of the T-PESS evaluation system process (self-assessment/goal setting, beginning-of-year conference, mid-year conference, and end-of-year conference) do the elementary principals perceive as being beneficial to their professional growth?

2. Of the five identified standards (instructional leadership, human capital, executive leadership, school culture, and strategic operations) measured on the T-PESS, what dothe elementary principals perceive as their greatest area of strength and their greatest area of need?

\section{Data Collection and Data Treatment}

The analysis of data involved organizing the data, coding for themes, and interpretingthe data. According to Creswell (2013), data analysis in qualitative research consists of preparing the data for analysis, reducing the amount of data into themes through coding, and, last, representing the data in tables. The process of data analysis provided order, structure, and interpretation;these steps are not isolated, but rather interrelated. Theprocess required the researcher to read, reread, make notes, and read again, which can make the process confusing and time consuming (Creswell, 2013), but it is necessary. NVivo software was used for coding, analyzing, and organizing qualitative data.

The analysis centered on categorizing emerging themes on the principals' perceptions of the usefulness of the T-PESS evaluation process as it relatedto their growth. The questionnaire and interview response data wereexamined to uncover connections, variances, and intricacies among the principal participants. NVivo software wasused to uncover patterns based on the data collected and questionnaire responses while maintaining the respondents' exact and authentic meanings. The researcher consistently made comparisons between each principal participant's response and interview explanations to identify any thematic consistencies or patterns. All survey responses and interview notes were analyzed and coded to determine central themes among elementary principal participants. According to Lunenburg and Irby (2008), the collection of data has several aspects, and they recommend that the researcher ensure that the collected data are protected and easily accessible. In transcribing the interviews, the use of a professional transcription system through voice software helped the researcher accurately and efficiently construct the narratives. The transcripts of the interviews were collected both on a cloud system on the computer and on a flash drive.

\section{Findings for Research Question 1}

Research Question 1 asked the following: What components of the T-PESS evaluation system process (selfassessment/goal setting, beginning-of-year conference, mid-year conference, and end-of-year conference) do elementary principals perceive as being beneficial for their professional growth? Three common themes emerged related to how elementary principals perceived the T-PESS evaluation process as beneficial for their professional growth. Figure 1 displays thethree emerging themes and the respective nodes within those themes.

\begin{tabular}{|l|l|l|}
\hline $\begin{array}{l}\text { Theme 1 } \\
\text { Goal Setting }\end{array}$ & $\begin{array}{l}\text { Theme 2 } \\
\text { Student Growth }\end{array}$ & $\begin{array}{l}\text { Theme 3 } \\
\text { Mid-Year Conference }\end{array}$ \\
\hline Goal Attainment & Student Outcome & Reflection \\
\hline Professional Growth & Student Growth Measure & Improve Performance \\
\hline Self-Identified & Individual Student Success & Formative \\
\hline Goal Establishment & Student Achievement & Ongoing \\
\hline Formulating Goal & Student Performance & Ratings \\
\hline Leadership Goal & & Substantiate Rating \\
\hline Campus Goal & & Support \\
\hline
\end{tabular}

Figure 1.Three themes and associated nodes that emerged in the analysis from the questionnaire and semi-structuredinterviews with study participants. 


\section{Emerging Theme 1}

The first emerging theme - goal setting — stemmed fromtestimonies and commentaries from participants related to the benefits of establishing goals. Participants shared their perspectives regarding how the establishment of clear and concise goals brings focus to their work. Moreover, the participants viewed goal setting as one of the most beneficial aspects of the T-PESS evaluation process. Linking goals to professional growth can change leadership behaviorandthoughts regarding student growth and may influence objectives/strategies indicated in the campus improvement plan. Furthermore, the principals discussedthe impact of setting goals that are not easily achieved, but stressed the importance of setting goals thathave a significant global impact on campus goals-leadership goals, professional growth, and student growth

\section{Emerging Theme 2}

The second emerging theme was student growth; participants expressed that student growth is what educators should be focused on because it shifts how assessments results are analyzed. The comments from participants indicated that every student should be experiencing growth, with most students achieving a year's growth based on the previous year's performance. Leadership strategies to enhance student performance, increase individual student success, and improve student outcomes were sentiments shared by participants as crucial aspects related to the overall growth of all students within a campus.

\section{Emerging Theme 3}

The third theme that emerged - the mid-year conference-was another component of the T-PESS evaluation process that elementary principal participants perceived to be relevant to the usefulness of T-PESS. The participants expressed theoverwhelming belief that the evaluation was formative in nature, with the ability to make adjustments to goals and improve ratings established in the rubric prior to the summative evaluation. The principals' comments indicated that they perceived the evaluation process as both reflective and formative based on their perception of the evaluation being about growthversus evaluative or punitive in nature.

\section{Findings for Research Question 2}

Research Question 2 asked the following: Of the five identified standards (instructional leadership, human capital, executive leadership, school culture, and strategic operations) measured by T-PESS, what do the elementary principals perceive as their greatest area of strength and their greatest area of need? The findings revealed five common themes that emerged that demonstrated how elementary principals perceived the T-PESS evaluation process as beneficial for their professional growth. Figure 2displays thefive emerging themes and the respective nodes within those themes.

\begin{tabular}{|c|c|c|c|c|}
\hline $\begin{array}{l}\text { Theme } \\
\text { 1InstructionalLea } \\
\text { dership }\end{array}$ & $\begin{array}{l}\text { Theme } \\
\text { 2Vision }\end{array}$ & $\begin{array}{l}\text { Theme } \\
\text { 3Leadership }\end{array}$ & $\begin{array}{l}\text { Theme } \\
\text { StrategicOperations }\end{array}$ & $\begin{array}{l}\text { Theme } \\
\text { Principalship }\end{array}$ \\
\hline $\begin{array}{l}\text { Student } \\
\text { Achievement }\end{array}$ & Shared Vision & $\begin{array}{l}\text { Shared } \\
\text { Leadership }\end{array}$ & Operational Aspects & High Performing \\
\hline $\begin{array}{ll}\text { Ensure } & \text { Student } \\
\text { Growth } & \\
\end{array}$ & $\begin{array}{l}\text { Campus } \\
\text { Vision }\end{array}$ & $\begin{array}{l}\text { Instructional } \\
\text { Practices }\end{array}$ & Managerial Aspects & Effective \\
\hline $\begin{array}{ll}\text { Maximize Student } \\
\text { Growth }\end{array}$ & Culture & $\begin{array}{l}\text { Teacher } \\
\text { Leaders }\end{array}$ & Day-to-Day Operations & $\begin{array}{l}\text { Duties } \\
\text { Responsibilities }\end{array}$ \\
\hline $\begin{array}{l}\text { Closing } \\
\text { Achievement Gap }\end{array}$ & & $\begin{array}{l}\text { Campus } \\
\text { Leaders }\end{array}$ & $\begin{array}{l}\text { Alignment } \\
\text { Resources }\end{array}$ & \\
\hline Teacher Growth & & & Budgetary Resources & \\
\hline
\end{tabular}

Figure 2.Five themes and associated nodes that emerged in the analysis from the questionnaire and semi-structured interviews with study participants.

\section{Emerging Theme 1}

The first emerging theme dealt with Standard 1, which is instructional leadership. The participants shared their perceptions on the importance of being an instructional leader since being a campus principal involves establishing clear goals, being a change agent, challenging the status quo, and expressinga sense of urgency to ensure student growth is maximized and the achievement gap in academic performance is closed for student groups. 


\section{Emerging Theme 2}

The second emerging theme wasvision; in this area, elementary principals shared their perspectives on the importance of the campus principal possessing the ability to articulate a clear vision. They indicated that a clear statement of the vision for the campus is critical to all stakeholders, including but not limited to teachers, students, parents, and community members. Theystressed the importance of constituentsfeeling empowered and having a sense of shared ownership to accomplish the educational organization's goal of ensuring every child learns. In addition, the participants expressed their personal vision for their campuses and described how a shared vision creates a culture of high expectations to produce high levels of learning for staff and students.

\section{Emerging Theme 3}

The third emerging theme was leadership; each of the principal participants gave some indication that one person cannot be held responsible for ensuring the education ofall the students. Shared responsibility was expressed as a means for fostering interdependence among all campus staff to make sure every child received what they needed regardless of what level they were performing. Moreover, this participants emphasized the theme ofteachers functioning as leaders on the campus to enhance student learning achievement.

\section{Emerging Theme 4}

The fourth emerging theme - strategic operations - was regarded by principal participants as being the least beneficial. The perceptions shared by the participants described the dimensions within this standard as being operational, managerial, and task oriented. Though most feltthat strategic operations areimportant, it does not focus on the importance of what encompasses being an educational leader. The perceptions shared in the interviews reflected that managerial responsibilities were what the principalship mainly consisted of in the past, such as being primarily responsible for making sure the building was clean, students got to class on time, every child received a schedule, drills were conducted consistently, and so forth. However, the testimonies indicated that the majority of the participants viewed the primary responsibility associated with their role as principal to be that of serving as an instructional leader responsible for ensuring high levels of learning for all students.

\section{Emerging Theme 5}

The fifth emerging theme-principalship - includedcomments from the participants about the importance of being a high performing and effective principal. The implication is that the principals equate their effectiveness withthe success of the teachers and students they support in the school. The participants shared that the standards and indicators identified in T-PESS are aligned to what they perceive as the global duties and responsibilities associated with their role as an elementary principal. The comments indicated a perception of the primary role of the principalship as being associated with being an instructional leader, and as a result, participants perceived the standards to be closely aligned to their work.

\section{Summary of Findings}

The perceptions of these elementary principals regarding which of the five standards they perceived as their greatest area of strength and greatest area of need was indicated in five common themes that emerged: (a) instructional leadership, (b) vision, (c) leadership, (d) strategic operations, and (e) principalship. The perceptions of these elementary principals reflected that indicators and dimensions within Standard 5, Strategic Operations, encompass their greatest strength, and Standard 1, Instructional Leadership,reflectedtheir greatest area of need. Based on the analyzed and coded data, the participantsfeltthat strategic operations areabout the managerial aspects of their duties/responsibilities, and they feel confident in accomplishing tasks associated with the standard. On the other hand, they perceive instructional leadership as the area thathas had the most impact on their knowledge and an area that requiresthem to grow and continuously improve their practices.

\section{References}

Anderson, E., \& Reynolds, A. (2015). The state of state policies for principal preparation program approval and candidatelicensure. Journalof Research on Leadership Education,10(3), 193-221. doi:10.1177/1942775115614292

Anderson, J. (2012, February 20). States try to fix quirks in evaluation systems. NY Times. Retrieved from http://www.nytimes.com/2012/02/20/education/states-address-problems-with-teacher-evaluations.html

Arar, K., Abramovitz, R., Daod, S., Awad, Y., \& Khalil, M. (2016). Teachers' perceptions of school principals' leadership styles and parental involvement. International Journal of Pedagogies \& Learning, 11(2), 132-144. doi:10.1080/22040552.2016.1227253 
Cisler, A., \& Bruce, M. (2013). Principals: What are their roles and responsibilities? Journal of School Counseling, $11(10), 1-27$.

Clandinin, J.,\& Connelly, M. (2000). Narrative inquiry: Experience and story in qualitative research. San Francisco, CA: Jossey-Bass.

Clifford, M., \& Ross, S. (2011). Designing principal evaluation systems: Research to guide decisionmaking.Naperville, IL:American Institute for Research.

Creswell, J. W. (2013). Qualitative inquiry and research design: Choosing among five approaches. Thousand Oaks, CA: Sage.

Creswell, J. W. (2014). Study guide for research design: Qualitative, quantitative, and mixed methods approaches. Thousand Oaks, CA: Sage.

Derrington, M. L., \&Sharratt, G. (2008). Evaluation of school principals using Interstate SchoolLeaders Licensure Consortium (ISLLC) standards. AASA Journal of Scholarship andPractice, 5(3), 20-29.

Dodson, R. L. (2015). Kentucky principal perceptions of the state's new teacher evaluation system: A questionnaire analysis. Educational Research Quarterly, 39(2), 53-74.

Dufour, R., \&Mattos, M. (2013). How do principals really improve schools? The Principalship, 70(7), 34-40.

Ebmeier, H. (2003). How supervision influences teacher efficacy and commitment: An investigation of a path model. Journal of Curriculum and Supervision, 18(2), 110-141.

Fullan, M. (2014). The principal: Three keys to maximizing impact. New York, NY: Wiley.

Fuller, E., \& Hollingsworth, L. (2014). A bridge too far? Challenges in evaluating principal effectiveness. Educational Administration Quarterly,50, 466-499. doi:10.1177/0013161X13506595

Goleman, D. (2004, January). What makes a leader? Harvard Business Review, 1-11.

Gunbayi, İ. (2011). Principals' perceptions on school management: A case study with metaphorical analysis. International Online Journal of Educational Sciences, 3, 541-561.

Hvidston, D.J., Range, B.G., \&McKim, C. A.(2015). Principals'perceptions regarding their supervision and evaluation. AASA Journal of Scholarship \& Practice, 12(2), 20-33. doi:10.1002/j.1556-6978.1993.tb00264.x

Krasnoff, B. (2015). Leadership qualities of effective principals. Portland, OR: Northwest Comprehensive Center.

Lunenburg, F. C., \& Irby, B. J. (2008). Writing a successful thesis or dissertation: Tips and strategies for students in the social and behavioral sciences. Thousand Oaks, CA: Corwin Press.

Magbool, R., Sudong, Y., \& Rashid, Y. (2017). The impact of emotional intelligence, project managers \& competencies, and transformational leadership on project success: An empirical perspective. Project Management Journal,48(3), 58-75.

Marcoulides, G. A., Heck, R. H., \&Papanastasiou, C. (2005). Student perceptions of school culture and achievement: Testing the invariance of a model. International Journal of Educational Management, 19(2), 140-152.

Marzano, R., Frontier, T., \& Livingston, D. (2011). A brief history of supervision and evaluation.

Retrieved from ASCDwebsite:http://www.ascd.org/publications/books/110019

/chapters/A-Brief-History-of-Supervision-and-Evaluation.aspx

Moore, J., Kuofie, M., Hakim, A., \& Branch, R. (2016). Teachers perceptions of principals as instructional leaders and student academic achievement in elementary schools. Journal of Marketing \& Management, 7(1), 1.

National Association of Elementary School Principals (NAESP). (2017). Rethinking principal evaluation. Retrieved from https://www.naesp.org/rethinking-principal-evaluation

National Association of Secondary School Principals (NASSP) and National Association of Elementary School Principals(NAESP). (2013). Leadership matters. Retrieved from http://www.naesp.org/sites/default/files/LeadershipMatters.pdf

Nickols, F. (2016). Four strategies for managing change. Retrieved from http://www.nickols.us/four_strategies.pdf

Quinn, R. E., \&Sonenshein, S. (2008). Four general strategies for affecting change in human systems. In T. G. Cummings (Ed.), Handbook of organization development (pp. 69-78). Thousand Oaks, CA: Sage.

Shepard, L. A., Penuel, W. R., \& Davidson, K. L. (2017). Design principles for new systems of assessment. Phi Delta Kappan,98(6), 47-52. doi:10.1177/0031721717696478

Texas Education Agency (TEA). (2017). Texas Principal Evaluation and Support System. Retrieved from https://tea.texas.gov/Texas_Educators

/Educator_Evaluation_and_Support_System/Texas_Principal_Evaluation_and_Support_System/

Tran, H. (2015). Assessing multiple stakeholders' perceptions of an effective principal evaluation system. Education Leadership Review, 16(2), 1-18.

Yavuz, M. (2010). Effectiveness of supervisions conducted by primary education supervisorsaccording to school principals' evaluations. Journal of Educational Research, 103,371-378. doi:10.1080/00220670903385338 